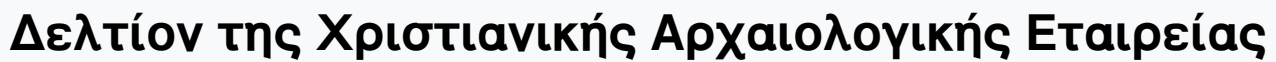

Tó 18 (1995)

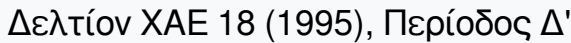

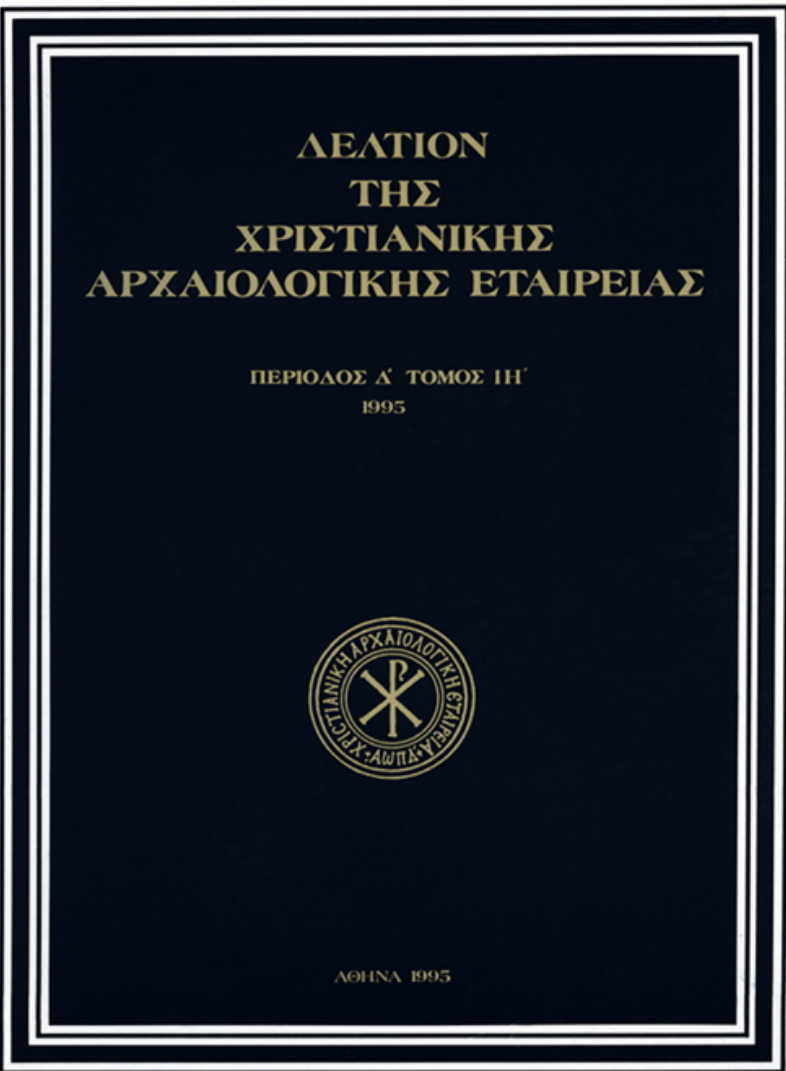

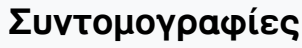

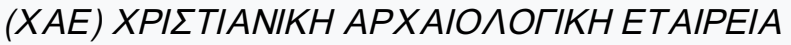

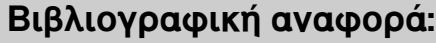

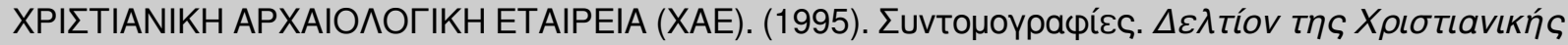

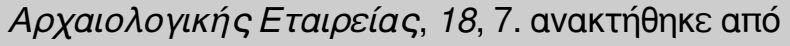

https://ejournals.epublishing.ekt.gr/index.php/deltion/article/view/5357 


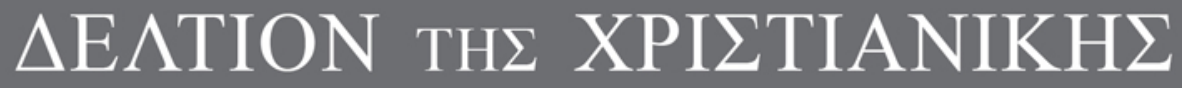 APXAIO $\Lambda$ OГIKH $\Sigma$ ETAIPEIA $\Sigma$}

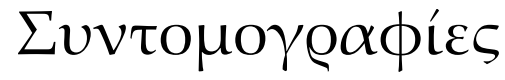

$\Delta \varepsilon \lambda \tau$ tíov XAE 18 (1995), Пeqíodos $\Delta^{\prime}$

A@HNA 1995 


\section{¿YNTОМОГРАФIЕ $\Sigma$}

\begin{tabular}{|c|c|c|c|}
\hline ABME & 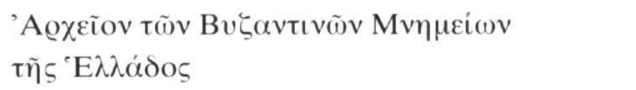 & $\begin{array}{l}\text { GOTWR } \\
\text { GRBS }\end{array}$ & $\begin{array}{l}\text { The Greek Orthodox Theological Review } \\
\text { Greek, Roman, and Byzantine Studies }\end{array}$ \\
\hline $\mathrm{A} \Delta$ & 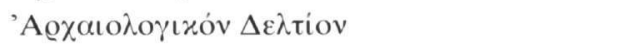 & $\Theta \varepsilon \sigma \sigma H \mu$ & 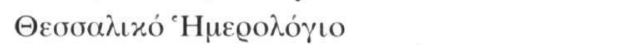 \\
\hline $\mathrm{AE}$ & 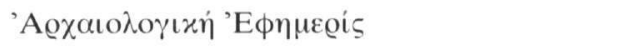 & $\Theta H E$ & 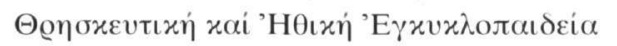 \\
\hline $\mathrm{AJA}$ & American Journal of Archaeology & IEE & 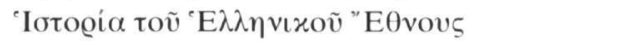 \\
\hline $\mathrm{AM}$ & Athenische Mitteilungen & IstF & Istanbuler Forschungen \\
\hline ANS & The American Numismatic Society & JHS & Journal of Hellenic Studies \\
\hline AnnUkrAcad & $\begin{array}{l}\text { The Annals of the Ukrainian Academy of Arts } \\
\text { and Sciences }\end{array}$ & $\begin{array}{l}\text { JÖB } \\
\text { JÖBG }\end{array}$ & $\begin{array}{l}\text { Jahrbuch der Österreichischen Byzantinistik } \\
\text { Jahrbuch der Österreichischen Byzantinischen }\end{array}$ \\
\hline ArtB & Art Bulletin & & Gesellschaft \\
\hline $\mathrm{BCH}$ & Bulletin de Correspondance Hellénique & JWarb & Journal of the Warburg and Courtauld \\
\hline BForsch & Byzantinische Forschungen & & Institutes \\
\hline BHG & Bibliotheca Hagiographica Graeca & Ke@xX@ov & 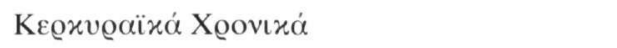 \\
\hline BMGS & Byzantine and Modern Greek Studies & 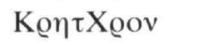 & 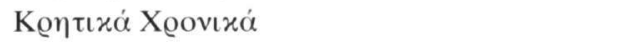 \\
\hline BNJ & Byzantinisch-Neugriechische Jahrbücher & $\Lambda \alpha x \Sigma \pi 0 v \delta$ & 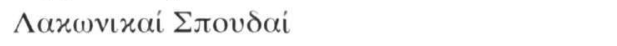 \\
\hline BSA & The Annual of the British School at Athens & LChrl & Lexikon der christlichen Ikonographie \\
\hline ByF & Byzantinische Forschungen & M.M. & Miklosich-Müller, Acta et diplomata graeca. \\
\hline $\mathrm{BZ}$ & Byzantinische Zeitschrift & & Res graecas italasque, illustrantia \\
\hline CahArch & Cahiers Archéologiques & MonPiot & Monuments et Mémoires, publiés par l'Acade- \\
\hline CahBalk & Cahiers Balkaniques & & mie des Inscriptions et Belles-Lettres, Fonda- \\
\hline \multirow[t]{2}{*}{ CorsiRav } & Corsi di Cultura sull'Arte Ravennate & & tion E. Piot \\
\hline & e Bizantina & NE & 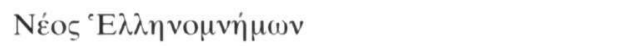 \\
\hline \multirow[t]{2}{*}{ CRAI } & Comptes-rendus des séances de l'Académie & OCA & Orientalia Christiana Analecta \\
\hline & des Inscriptions et Belles-Lettres & ПАЕ & 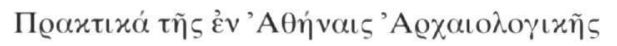 \\
\hline CSHB & Corpus Scriptorum Historiae Byzantinae & & ${ }^{\circ}$ Etargeias \\
\hline \multirow[t]{2}{*}{ DACL } & Dictionnaire d'Archéologie Chrétienne & PG & Patrologia cursus completus, Series graeca \\
\hline & et de Liturgie & RA & Revue Archéologique \\
\hline$\triangle \mathrm{AEK}$ & 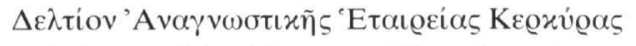 & RAC & Reallexikon für Antike und Christentum \\
\hline \multirow[t]{2}{*}{$\triangle \mathrm{E} Г \mathrm{EE}$} & 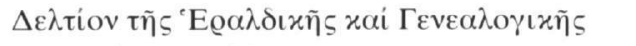 & $\mathrm{RbK}$ & Reallexikon zur byzantinischen Kunst \\
\hline & 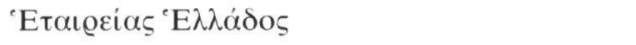 & RDAC & Report of the Department of Antiquities, \\
\hline$\Delta \mathrm{IA}$ & $\Delta \varepsilon \lambda \tau i ́ o v ' I o v i o v ' A x \alpha \delta \eta \mu i \alpha \varsigma$ & & Cyprus \\
\hline \multirow[t]{2}{*}{$\triangle \mathrm{IEE}$} & 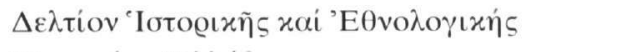 & RE & Paulys Realencyclopädie der classischen \\
\hline & 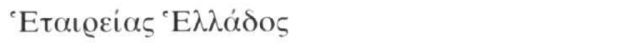 & & Altertumswissenschaft \\
\hline \multirow[t]{2}{*}{$\triangle \mathrm{XAE}$} & 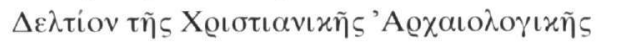 & REB & Revue des Etudes Byzantines \\
\hline & 'Etaıgias & RQ & Römische Quartalschrift für christliche \\
\hline DOP & Dumbarton Oaks Papers & & Altertumskunde und (für) Kirchengeschichte \\
\hline DOS & Dumbarton Oaks Studies & RSBN & Rivista di Studi Bizantini e Neoellenici \\
\hline DOT & Dumbarton Oaks Texts & SNG & Sylloge Nummorum Graecorum \\
\hline $\operatorname{EEB} \Sigma$ & 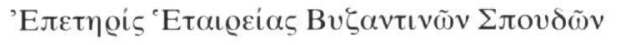 & SubHGr & Subsidia Hagiographica Graeca \\
\hline \multirow[t]{2}{*}{ 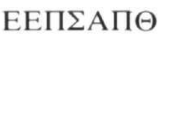 } & 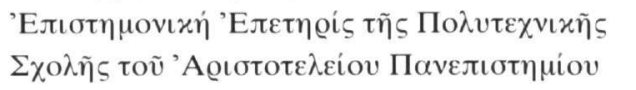 & Synaxarium CP & $\begin{array}{l}\text { Synaxarium Ecclesiae Constantinopolitanae. } \\
\text { Propylaeum ad Acta SS Novembris }\end{array}$ \\
\hline & $\Theta \varepsilon \sigma \sigma \alpha \lambda o v i x \eta \varsigma$ & TIB & Tabula Imperii Byzantini \\
\hline \multirow[t]{2}{*}{ EMME } & 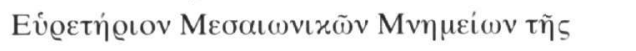 & $\mathrm{TM}$ & Travaux et Mémoires \\
\hline & 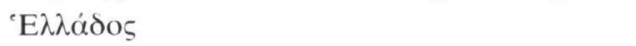 & TU & Texte und Untersuchungen zur Geschichte \\
\hline $\mathrm{EO}$ & Echos d'Orient & & der altchristlichen Literatur \\
\hline FelRav & Felix Ravenna & VizVrem & Vizantijskij Vremmenik \\
\hline GBA & Gazette des Beaux-Arts & ZRVI & Zbornik Radova Vizantološkog Instituta \\
\hline
\end{tabular}

